\title{
Effects of Reduced Pressure and Coat Permeability on Casting Characteristics of Magnesium Alloy in Evaporative Pattern Casting Process*
}

\author{
Kyong-Whoan Lee ${ }^{1}$, Gue-Serb Cho ${ }^{1}$, Kyeong-Hwan Choe ${ }^{1}$, \\ Hyung-Ho Jo ${ }^{1}$, Akira Ikenaga ${ }^{2}$ and Sadatoshi Koroyasu ${ }^{3}$ \\ ${ }^{1}$ Advanced Material R\&D Center, Korea Institute of Industrial Technology, Incheon 406-800, Korea \\ ${ }^{2}$ Department of Metallurgy and Materials Science, Graduate School of Engineering, \\ Osaka Prefecture University, Sakai 599-8531, Japan \\ ${ }^{3}$ Department of Mechanical and Precision System, School of Science and Engineering, \\ Teikyo University, Utsunomiya 320-8551, Japan
}

A magnesium alloy was adopted to an evaporative pattern casting (EPC) process to combine advantages of each. In the present study, foam patterns were cast at a top gating system under atmospheric and reduced pressure to evaluate casting characteristics of AZ91D to develop a complete EPC process for high productivity of magnesium alloy castings. Filling time and temperature of molten metal were measured during mold filling. It was recognized that the average filling velocity was affected by the difference of the coating material and the degree of reduced pressure. The grain size of the magnesium alloy was slightly dependent on the degree of reduced pressure. It was considered that the application of the high reduced pressure, which changed the shape of melt surface from convex to concave, was related to the occurrence of internal defects such as cold shut laps or folds in the casting. [doi:10.2320/matertrans.47.2798]

(Received April 14, 2006; Accepted September 1, 2006; Published November 15, 2006)

Keywords: evaporative pattern casting process, AZ91D, magnesium alloy, reduced pressure, filling velocity, casting defect

\section{Introduction}

Magnesium alloys have many advantages in automotive applications because of their low density and high specific strength. They have thus been studied to produce a real component using the die casting process. However, the application to a prototype with low production levels and a complex shape with a core or reverse taper is difficult in the die casting method. Therefore, an alternative casting process should be developed in order to extend the applications of magnesium alloys in the automotive industry. ${ }^{1)}$ The evaporative pattern casting (EPC) process is very attractive, particularly in the casting of thin-wall, complex shapes or smooth surface components. ${ }^{2)}$ Furthermore, burr finishing of magnesium alloy is very difficult, so an EPC process that eliminates the casting fin would be very useful. In addition, the EPC process is still attractive in spite of the present high price of magnesium alloys, because it is possible to obtain a complex shaped casting with high added values which can not be obtained by the die casting method.

Recently, many studies for using aluminum and ferrous alloys in the EPC process have been conducted but very few studies on magnesium alloys have been reported.

In the present study, in order to examine a method for producing a sound magnesium alloy casting using the EPC process, the effects of reduced pressure and coat permeability on casting characteristics such as molten metal flow, casting defects, casting surfaces and microstructures were considered, in the EPC process of AZ91D in the JIS used most widely in magnesium casting alloys.

*This Paper was Originally Published in Japanese in J. JFS 77 (2005) 841846.

\section{Experimental Procedure}

\subsection{Production and shape of evaporative pattern}

Figure 1 shows the evaporative polystyrene (EPS) pattern in this study. A stairway type pattern was prepared in order to examine the effect of the casting thickness on the casting
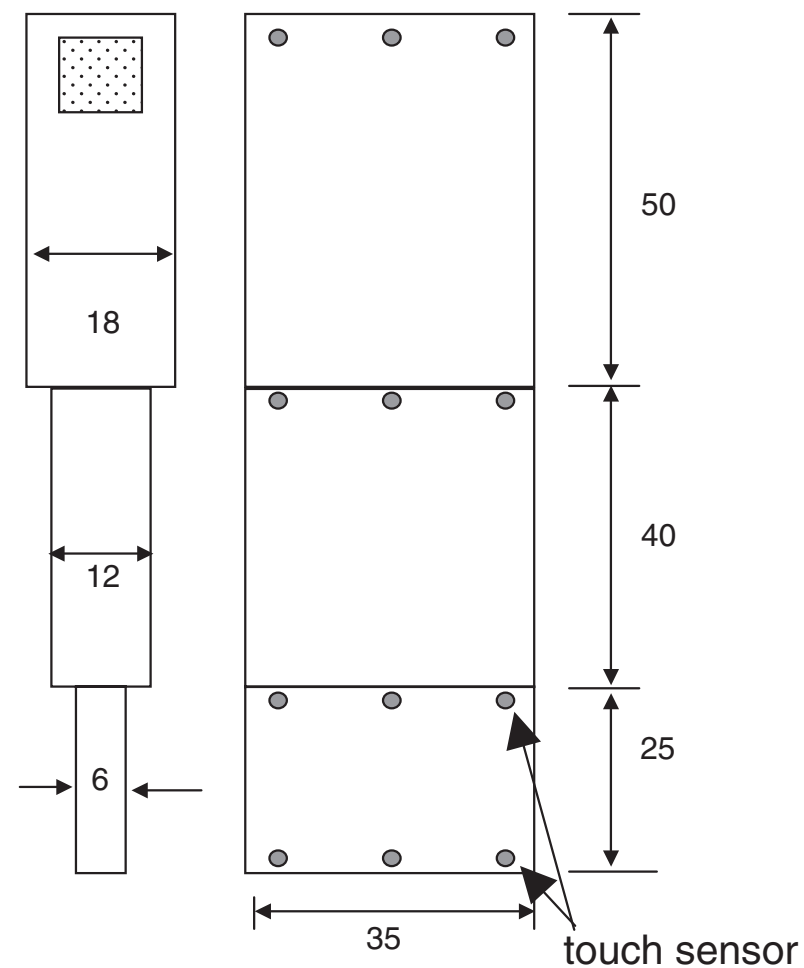

Fig. 1 Dimensions of EPS pattern and positions for detecting metal flow. (units:mm). 
Table 1 Properties of refractory coatings.

\begin{tabular}{lccc}
\hline Properties & Coat A & Coat B & Coat C \\
\hline Permeability & 5.2 & 0.3 & 0.14 \\
Baume/degree & 84 & 76 & 50 \\
\hline
\end{tabular}

microstructure. The average diameter of EPS beads was $0.5 \mathrm{~mm}$, and the expansion ratio of the EPS pattern was 42 times (density $25 \mathrm{~kg} / \mathrm{m}^{3}$ ). The stairway type EPS pattern is $35 \mathrm{~mm}$ wide, and its height from the top was set to 50, 40 and $25 \mathrm{~mm}$ with thickness of 18,12 and $6 \mathrm{~mm}$. The stairway type EPS pattern and the gating part were made from the EPS block by hot wire cutting.

\subsection{Coating conditions}

Three coat materials with different permeabilities were used in this study as shown in Table 1. Each coat is a highly insulating coat for light metals such as an aluminum alloy.

The permeabilities of coats B and C are standard for highly insulating coat, but that of coat A is extremely high. The EPS pattern was dipped into the coat slurry and dried at the room temperature for $24 \mathrm{~h}$. The thickness of the coat layer was measured by calipers to be 0.6 to $1.0 \mathrm{~mm}$ after drying. The uncoated pattern was also prepared.

\subsection{Casting design and conditions of melting and pour- ing}

Figure 2 shows the casting design in this work and the positions of the thermocouple and the touch sensor inserted into the EPS pattern for measuring the temperature and the molten metal flow. A top pouring system was selected. Three stairway type EPS patterns coated with different coats were aligned radially to the center of the hollow ceramic sprue of $150 \mathrm{~mm}$ height. The cluster was assembled by connecting these. Three EPS patterns are poured almost at the same time with the same molten metal in the assembled cluster. The differences of conditions of the three EPS patterns, such as the pouring temperature, are not significant. The gate that connected the EPS pattern with the sprue was made from the same material as the EPS pattern and had a cross-section of $10 \times 10 \mathrm{~mm}$ and a length of $20 \mathrm{~mm}$.

The assembled cluster was set in a steel mold flask $(400 \times 400 \times 500 \mathrm{~mm})$. Silica sand produced in Vietnam with AFS grain fineness number 40 was poured into the flask and compacted by an one-dimensional vibrator operating vertically.

After compacting, a plastic film was used to cover the top of the flask to maintain the reduced pressure inside. Touch sensors were inserted into the EPS pattern for measuring the filling time of the molten metal front (melt surface) during mold filling. The touch sensors were steel wires of $0.5 \mathrm{~mm}$ in diameter set up as illustrated in Figs. 1 and 2. The average velocity of the melt surface (filling velocity) was defined from the time differences at which the melt surface reached each touch sensor.

The pouring the molten metal from the ladle was done by a pouring cup of $30 \mathrm{~mm}$ in height, which was the commercial EPS foam coated with refractory coating materials, and finally baked at $323 \mathrm{~K}$ for approximately $12 \mathrm{~h}$. In order to measure the temperature response during mold filling, type $\mathrm{K}$

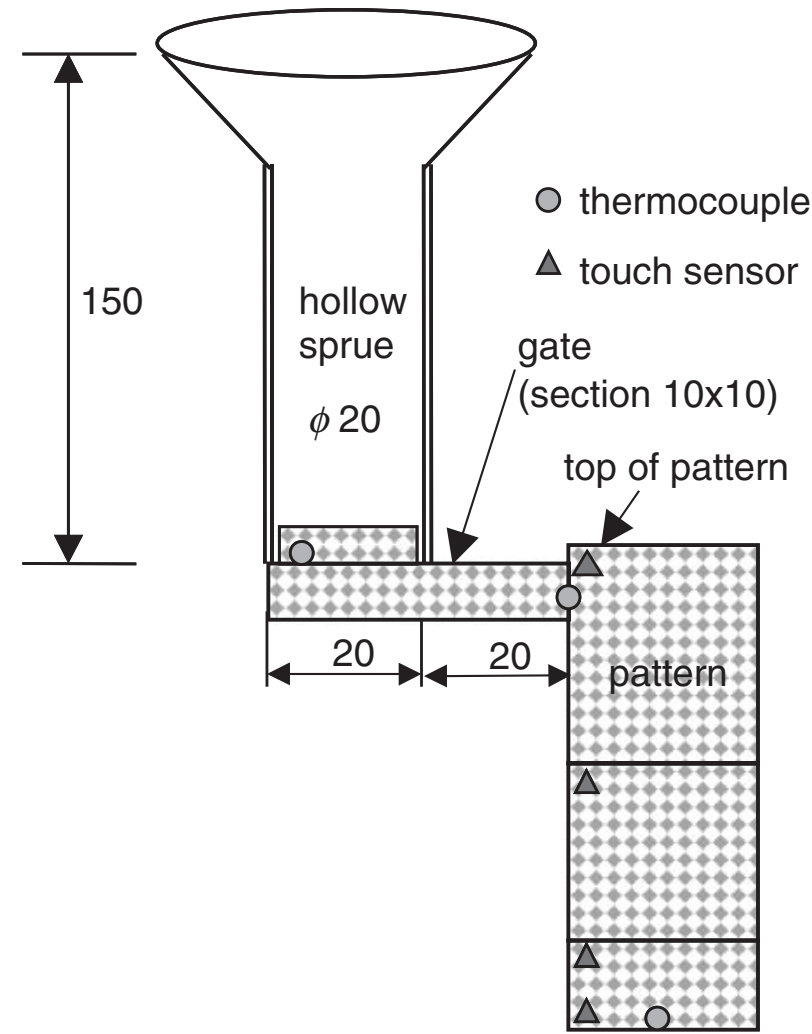

Fig. 2 Schematic diagram for measuring filling time and temperature of molten metal. (units:mm).

thermocouples were set at the sprue base, the inlet and the bottom of the EPS pattern as shown in Fig. 2. The thermocouples were $0.5 \mathrm{~mm}$ in diameter and were shielded by the two-holes protection tube of $3 \mathrm{~mm}$ in the outside diameter, but thermocouple junction was unprotected.

AZ91D in the JIS magnesium alloy ingots were melted and superheated over $983 \mathrm{~K}$. The temperature is controlled to the pouring temperature of $973 \mathrm{~K}$ in a $20 \mathrm{~kg}$ steel crucible using a holding furnace. A gas mixture of $\mathrm{CO}_{2}$ and $\mathrm{SF}_{6}$ was used to purge the furnace and covered the melt surface throughout the whole casting operation.

The atmospheric pressure and the differential pressure with atmospheric pressure (reduced pressure) of $6.7 \mathrm{kPa}$ and $13.3 \mathrm{kPa}$ were applied as the condition of the pressure in the flask.

In order to check for casting defects such as cold shut laps or folds, the casting surface and the cross-section of castings were visually observed. The average grain size of the magnesium alloy in different cross-sections of the stairway type casting was measured from optical microstructures by the sectioning method.

\section{Experimental Results and Discussion}

\subsection{Effects of reduced pressure and coat permeability on the filling velocity}

There is no significant difference in the specific heat between the molten magnesium alloy and the molten aluminum alloy, considering the thermal data of their pure metals. ${ }^{3)}$ The pouring temperature and the solidus temperature of magnesium alloy are also almost the same as those of 


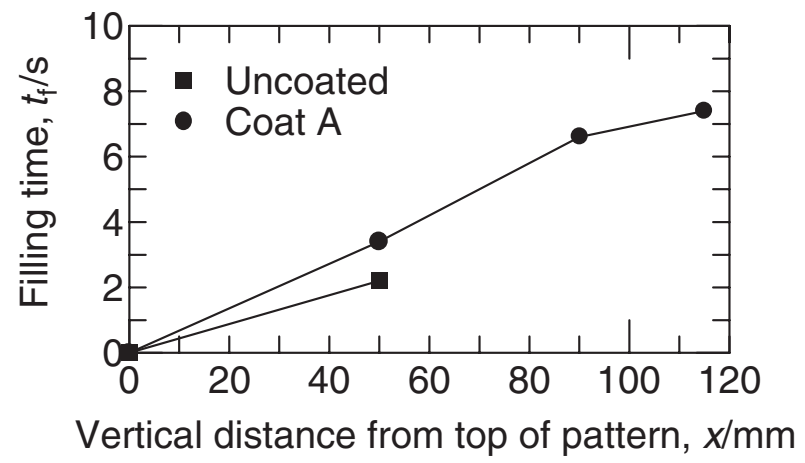

Fig. 3 Effect of coating materials on filling time from top of EPS pattern without reduced pressure.

aluminum alloy. However, as the density of magnesium alloy is about $2 / 3$ of that of aluminum alloy, a melt head which depresses the back pressure in the mold during the pouring is not obtained sufficiently, and also the specific heat per volume of the molten magnesium alloy is low. The latent heat of solidification per volume of magnesium alloy is about $1 / 3$ that of aluminum alloy, based on a comparison of the properties of those pure metals. ${ }^{3)}$ From these considerations, it is assumed that the temperature drops of metal during mold filling and after formation of the primary crystals of magnesium alloy are more remarkable than those of aluminum alloy.

The EPC process is a volume replacement process in which molten metal decomposes the pattern material with its latent heat. When this process is adapted for casting magnesium alloy, a casting problem such as a misrun is occurred in the mold filling.

In the present study, the filling velocity was evaluated under various reduced pressure conditions. Figure 3 shows the filling time $t_{\mathrm{f}}$ of the molten magnesium alloy as a function of vertical distance $x$ from the top of the EPS pattern for different coating conditions without reduced pressure.

The molten magnesium alloy was stopped at the position of $85 \mathrm{~mm}$ from the gate, and did not reach the touch sensor at the position of $90 \mathrm{~mm}$ for the uncoated EPS pattern. On the other hand, a complete filling is obtained for coat A with extremely high permeability. The average filling velocity of molten magnesium alloy for coat A condition is calculated $16 \mathrm{~mm} / \mathrm{s}$ from the difference of time response between two measuring points. Coat $\mathrm{B}$ and Coat $\mathrm{C}$ have much lower permeability than Coat $\mathrm{A}$, so the flow front of the molten magnesium alloy stopped at the upper position of the stairway type EPS pattern. There were the poorest mold filling observed in the present study.

The complete mold filling is done for coat A even though the mold filling velocity for coat A was slower than that for an uncoated EPS pattern. In contrast, the mold filling could not be completed for the uncoated case. The thermal conductivity of a coat for light metal alloys such as aluminum alloy is about $1 / 3$ of that of the general coat used for cast iron. ${ }^{4)}$ The authors have found that when the coat for light metal alloys was used for casting aluminum alloy, the temperature drop of the melt surface in the direction of melt flow is about $1 / 2$ of that when the general coat is used. ${ }^{5)}$ The thermal conductivity of the generally used coat is almost the

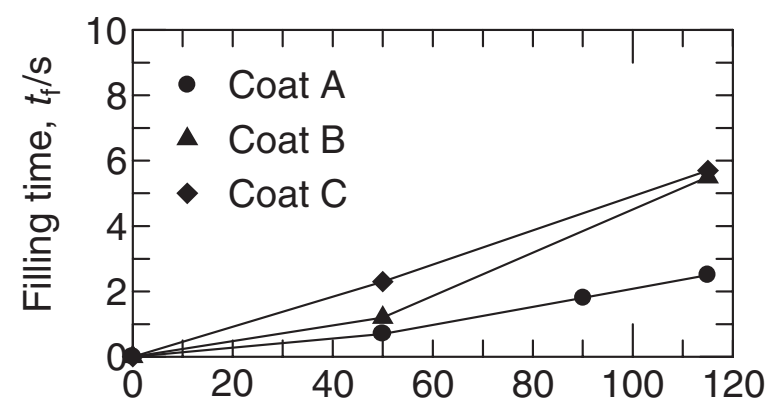

Vertical distance from top of pattern, $x / \mathrm{mm}$

Fig. 4 Effect of coating materials on filling time from top of EPS pattern with reduced pressure of $6.7 \mathrm{kPa}$.

same as that of the packed bed of silica sand. ${ }^{6)}$ When the contact condition with the molten metal is not considered, the heat absorption of the mold from molten metal for the uncoated pattern is almost the same as that for the coated pattern with the generally used coat. From these results, when the coat for a light metal alloy such as aluminum alloy was used, the temperature drop of melt surface decreases to about $1 / 2$, and the fluidity length estimates to be increase about 2 times, in comparison with the case of the uncoated EPS pattern. The flow resistance of the decomposition gas in a coat causes the filling velocity for the coated EPS pattern to be lower than that fot the uncoated pattern. However the complete mold filling of coat A was due to the extremely high permeability as shown in Table 1 , and the decrease of temperature drop of melt surface. The misrun in the cases of coats $\mathrm{B}$ and $\mathrm{C}$ were due to lower permeability than coat $\mathrm{A}$.

Figure 4 shows the filling time for the reduced pressure of $6.7 \mathrm{kPa}$. The average filling velocity is ranged from 21 to $46 \mathrm{~mm} / \mathrm{s}$ for all coating conditions, which is remarkably higher than that without reduced pressure shown in Fig. 3.

The mold filling velocity of coat A with a high permeability was found to be faster by more than 3 times compared to that without reduced pressure. The effect of the reduced pressure was obvious to improve misruns for low permeability coats such as coats B and C.

Figure 5 shows the filling time for the reduced pressure of $13.3 \mathrm{kPa}$. The mold filling velocity is ranged from 26 to $58 \mathrm{~mm} / \mathrm{s}$, which is approximately higher than that for the reduced pressure of $6.7 \mathrm{kPa}$. However, the molten metal penetrated into the sand in the case of the uncoated pattern which exhibited the highest filling velocity.

In the conditions of coat $\mathrm{A}$ with the reduced pressure of $13.3 \mathrm{kPa}$, the filling velocity is smaller than the case of the reduced pressure of $6.7 \mathrm{kPa}$ at the $90 \mathrm{~mm}$ distance. For the relatively high reduced pressure of $13.3 \mathrm{kPa}$, it is considered that the phenomenon which is called "forward flow of molten metal" easily happens. Namely, the molten metal flows along the coat wall prior to the inner pattern. Generally, there is the thermal decomposition gas layer that extends to the whole cross-section between the melt surface and the undecomposed pattern. The region made by the gas layer called as the cavity in this paper. When the molten metal flows into the stairway type pattern from the gate, there is only a very thin thermal decomposition gas layer. So the pattern almost contacted with the melt surface, and the cavity was not 


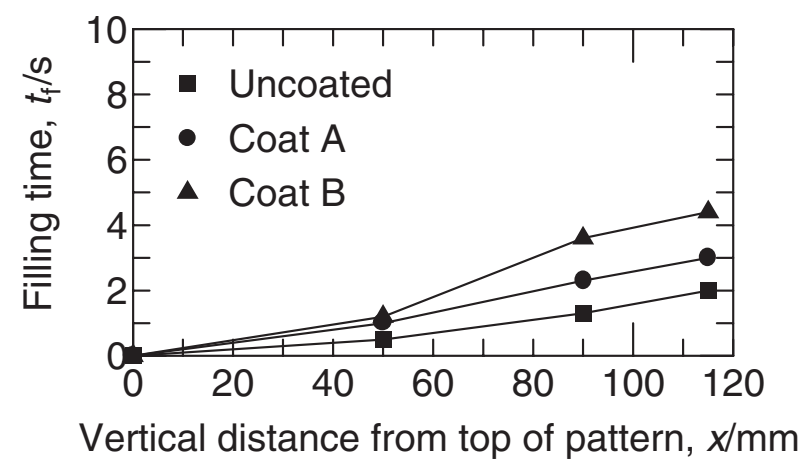

Fig. 5 Effect of coating materials on filling time from top of EPS pattern with reduced pressure of $13.3 \mathrm{kPa}$.

formed. When the reduced pressure of $13.3 \mathrm{kPa}$ is applied under those conditions, the reduced pressure affects only the vicinity of the coat wall. Therefore, "forward flow of molten metal" in which the molten metal flows as a concave surface along the coat wall is observed. As a result, the molten metal flow was primarily delayed, because the void of coat wall, which is used to discharge the decomposition product, is closed by the reduced pressure. The temperature drop of the molten metal that flows locally near the coat wall increases due to the heat transfer into the coat. Furthermore, the filling velocity was decreased by the back pressure due to the thermal decomposition gas. The effect of "forward flow of molten metal" is larger than other factors mentioned above in the case of the reduced pressure of $13.3 \mathrm{kPa}$.

The filling velocity for the uncoated pattern is higher than that for the coated pattern, because the discharge velocity of the decomposition product to the sand mold for the uncoated pattern is higher than the case for the coated pattern.

\subsection{Effect of reduced pressure on surface morphology of casting}

Figure 6 shows the surface morphologies of castings for a high permeability coat $\mathrm{A}$ at different reduced pressures. A trace of liquefied residues generated by thermal decomposition of the EPS pattern is observed on the surface of the casting in the cases without reduced pressure shown in Fig. 6(a).

In the case of without reduced pressure, the time which the melt surface reaches the positions of the touch sensor compared with the case under reduced pressure of $6.7 \mathrm{kPa}$ takes about 3 times, because of the low melt head of magnesium alloy, as shown in Figs. 3 and 4. The temperature of the melt surface is remarkably decreased by the chilling effect of the liquefied EPS pattern, the heat loss of the molten metal due to the thermal decomposition of the EPS pattern, and the heat conduction into the sand mold. Therefore, it is difficult to thermally decompose the polystyrene to the lowlevel hydrocarbon immediately at the melt surface. It is also more difficult to evaporate the polystyrene than the conditions under the reduced pressure. The liquefied decomposition products between the casting surface and the coat probably did not penetrate into the coat and the sand mold during mold filling but remained as a carbon residue.

When the reduced pressure of 6.7 or $13.3 \mathrm{kPa}$ is applied, a good surface is obtained showing the replica morphology of the bead texture.

The EPC process is a substitution process of the molten metal and the EPS pattern. When the EPS pattern starts the thermal decomposition in the case of the cast iron in which the molten metal temperature is high, it first decomposes at about $673 \mathrm{~K}$ in the liquefied styrene monomer $\left(\mathrm{C}_{8} \mathrm{H}_{8}\right)$, and then decomposes into a low-level hydrocarbon while increasing the temperature. Finally, it decomposes into a hydrocarbon gas of $\mathrm{C}_{5}-\mathrm{C}_{1}$. A cavity of considerable size not excepting the liquefied decomposition product layer has been generated at the region of substitution of the molten metal and the pattern having nothing to do with the reduced pressure conditions. ${ }^{7)}$

However, for a light metal such as an aluminum alloy in which the pouring temperature is relatively low, there is little cavity in the region of substitution of the molten metal and the pattern. ${ }^{8)}$ For aluminum alloy casting, cavity formation under the reduced pressure is seldom reported, since the reduced pressure is not generally applied.

The pouring temperature of the magnesium alloy in this study is almost the same as that of aluminum alloy in the EPC process. Therefore, there is little cavity caused by the thermal decomposition gas at the region of substitution of the molten metal and the pattern without reduced pressure, as well as the case of the aluminum alloy mentioned above.

Under reduced pressure, the cavity volume is large based on the Le Chatelier's law, even if the generation ratio of the gaseous decomposition produce is smaller than that without reduced pressure. In addition, the liquefied decomposition products of $\mathrm{C}_{8}-\mathrm{C}_{6}$ are easily gasified by evaporation. From those considerations, the liquefied decomposition product is able to be completely absorbed into the sand mold through the coat.

In the case of the EPC process using a magnesium alloy, whose melt head and specific heat per volume are less than an aluminum alloy, a sound morphology of castings was obtained by applying the reduced pressure below the reduced pressure at which "forward flow of molten metal" occurs.
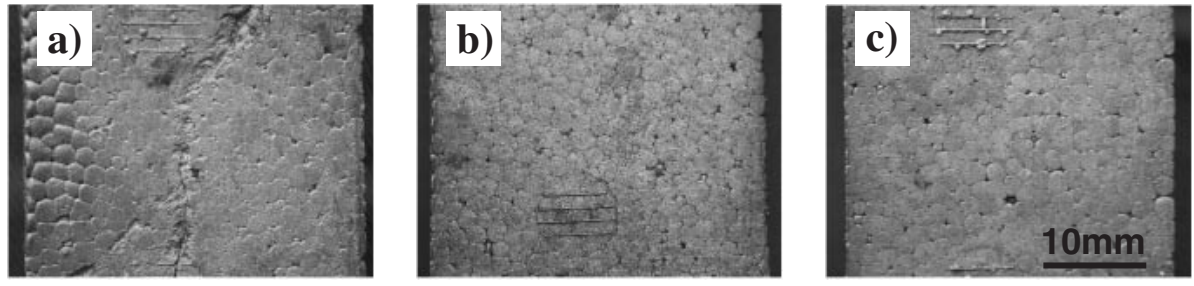

Fig. 6 Effect of reduced pressure on casting surface appearance for coat A, (a) without reduced pressure, (b) with reduced pressure of $6.7 \mathrm{kPa}$ and (c) $13.3 \mathrm{kPa}$. 
a)

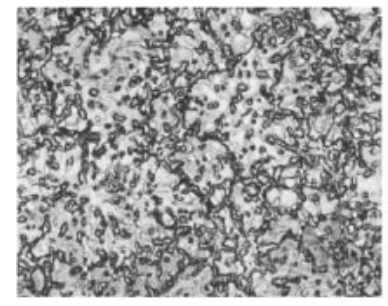

b)

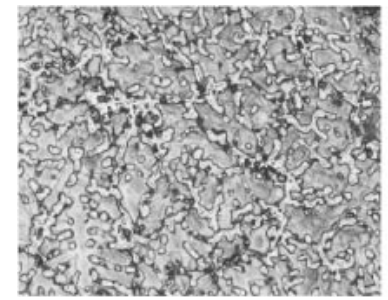

D: $18 \mathrm{~mm}$
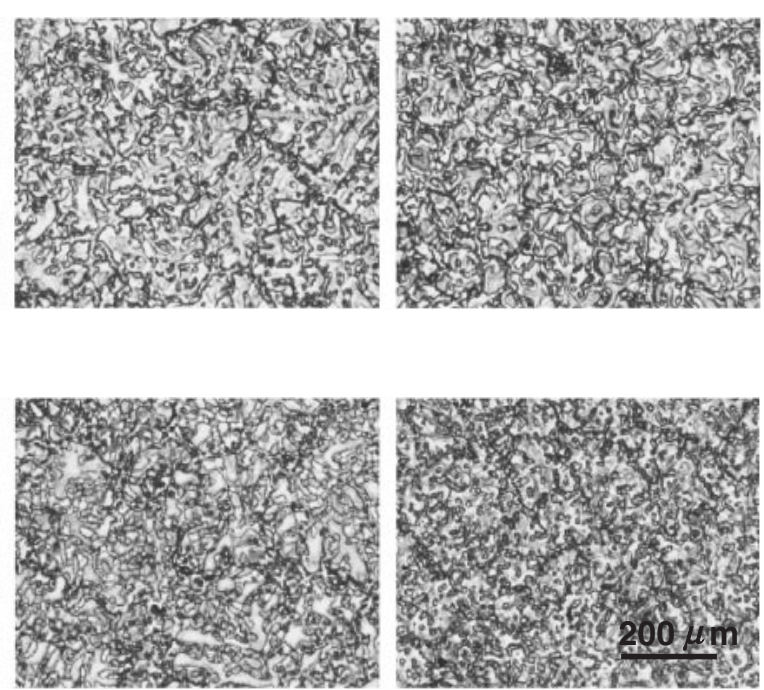

$12 \mathrm{~mm}$

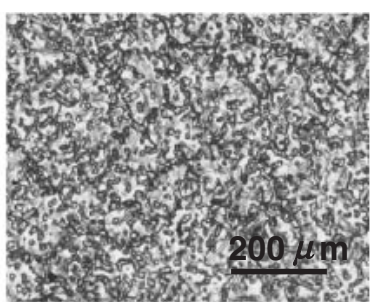

$6 \mathrm{~mm}$

Fig. 7 Optical cross-sectional microstructures of AZ91D casting in different thickness(D) for coat A without reduced pressure (a) and with reduced pressure of $13.3 \mathrm{kPa}(\mathrm{b})$.

\subsection{Effect of reduced pressure on casting microstruc- ture}

Figure 7 shows the optical microstructures of different cross-sections of the stairway type casting.

The average grain size is decreased a little for the thinner cross-section. There are 100 to $140 \mu \mathrm{m}$ in the case without reduced pressure and 80 to $110 \mu \mathrm{m}$ under reduced pressure. The effect of the casting thickness on the average grain size was relatively small for all reduced pressure conditions. Microstructures of castings under reduced pressure were slightly finer in previous research ${ }^{2)}$ than that without reduced pressure. As one of the causes, when the reduced pressure is applied, the resistance of heat transfer due to air gaps, etc. decreases with increasing adhesion of the interface of the coat and the molten metal, thereby increasing the cooling velocity of the molten metal. ${ }^{9)}$ As another cause, when the reduced pressure is applied, with increasing the filling velocity, the molten metal contacts with the mold in which there is less heat absorption. Thereby the cooling velocity of molten metal increases.

\subsection{Substitution of molten metal and pattern under reduced pressure}

The temperature responses $T$ during mold filling measured by type $\mathrm{K}$ thermocouples set at the sprue base, the inlet and the bottom of EPS pattern are illustrated in Fig. 8 as a function of the elapsed time $t$. The results in Fig. 8 were obtained for high permeability coat A under reduced pressure condition that a sound casting was produced. The maximum temperature was $906 \mathrm{~K}$ at the sprue base, $861 \mathrm{~K}$ at the inlet and $823 \mathrm{~K}$ at the bottom of the EPS pattern (final filling point). There are the response delay of the thermocouple and the effect of heat transfer to the thermocouple protection tube. However the temperatures can be considered to be melt surface temperatures ${ }^{5,10)}$ because these factors are little. The temperature drop at the melt surface along the melt flow direction seems to result from the heat absorption due to

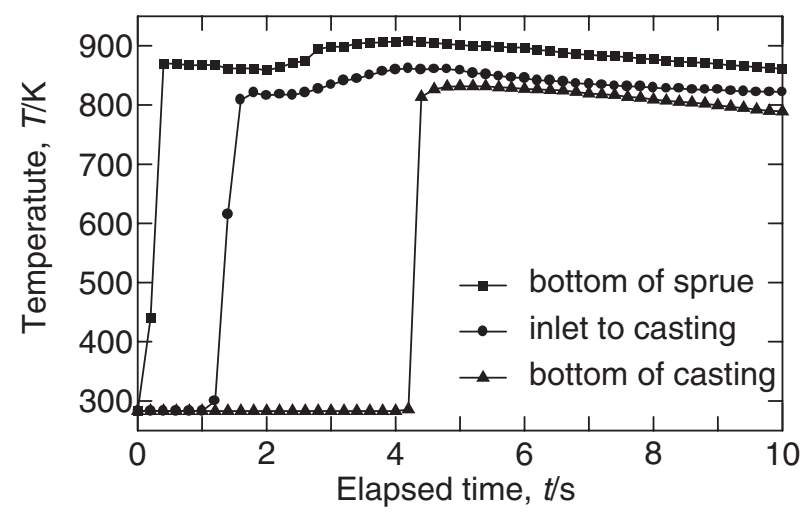

Fig. 8 Typical temperature curves on mold filling at each thermocouples set into pattern with coat $A$ under reduced pressure of $6.7 \mathrm{kPa}$.

thermal decomposition of the pattern and heat transfer into the mold. The melt surface reached the thermocouples at 0.4 , 1.5 and $4.4 \mathrm{~s}$, respectively. It took $1.1 \mathrm{~s}$ for the molten metal to pass the $20 \mathrm{~mm}$ long gate, so the average filling velocity was calculated $18 \mathrm{~mm} / \mathrm{s}$. This filling velocity is considerably lower than that for the stairway type pattern from the result of Fig. 4. This can be explained as follows. When the molten metal thermally decomposes the EPS pattern while penetrating into the pattern, the radiant heat from the melt surface as the driving force is transmitted to not only the EPS surface through the thermal decomposition gas layer but also the coat which contacted with the gas layer. The cross-section of the gate is 15 to $50 \%$ of that of the stairway type pattern. In addition the perimeter length of the molten metal per crosssection at the gate is greater than that at the pattern. Therefore, the ratio of the heat for thermal decomposition of the pattern to the radiant heat from the molten metal decreases. The duration time from the response of a thermocouple to indicating the molten metal temperature was about $0.4 \mathrm{~s}$ at the gate end. The response time of a thermocouple almost coincides with the time when the 


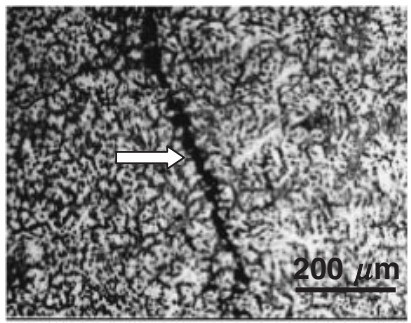

a)

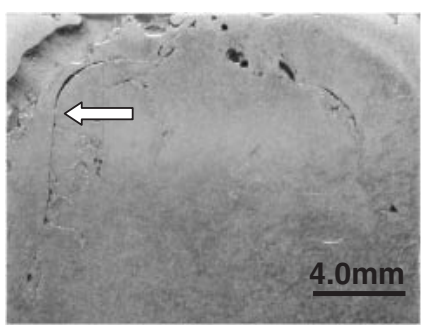

b)
Fig. 9 Casting defects of cold lap in the thin section (a) and the thick section (b) under reduced pressure of $13.3 \mathrm{kPa}$.

thermocouple began to receive the radiant heat from the molten metal directly, by the thermal decomposition of the pattern at the tip of the thermocouple. Neglecting the effect of the response delay of the thermocouple, the thickness of the thermal decomposition gas layer at the gate end will be less than about $7 \mathrm{~mm}$, and that at the pattern will be less than about $12 \mathrm{~mm}$ by an approximate calculation.

\subsection{Relationship between reduced pressure and casting defects}

In the previous paper, the effect of reduced pressure on the melt surface shape was studied in AZ91D magnesium alloy. ${ }^{11)}$ Under reduced pressure, the shape of the melt surface was changed from convex to concave type as described in section 3.1. It has been reported that a pointed convex melt surface was formed in the cases of top pouring and no reduced pressure. ${ }^{12,13)}$ However, the molten metal flowed primarily along the coat wall by priority under reduced pressure. Increasing the degree of reduced pressure, this tendency becomes remarkable and the liquid decomposition products tend to accumulate at the concave metal surface. Then it may be trapped within the solidified metal, which may contain liquid residuals besides some defects such as laps or porosities.

Figure 9 shows the casting defects observed in the different cross-sections of casting under reduced pressure of $13.3 \mathrm{kPa}$. The typical defects are obserbed from Fig. 9, such as the formation of cold laps or folds in the thin crosssection (a) and the double layer and the porosity in the thick cross-section (b). These are caused by the phenomenon of the molten metal flowing primarily along the coat wall.

\section{Conclusion}

The effects of the reduced pressure and the coat permeability on the casting characteristics of AZ91D magnesium alloy in the EPC process were examined. The following conclusions were drawn from this experimental study.

(1) In the condition of without reduced pressure and low permeability coat, the mold filling was stopped at the runner. A complete mold filling was obtained in the coat with high permeability, but poor mold filling was found in the uncoated condition. On the other hand, in the condition with the reduced pressure of $6.7 \mathrm{kPa}$, a complete mold filling was obtained and the filling velocity increased whth increasing the coat permeability for all coating conditions.

(2) In the case of the high permeability coat $\mathrm{A}$ and the reduced pressure of 6.7 or $13.3 \mathrm{kPa}$, the carbon defects observed by the condition without reduced pressure was disappeared and a sound surface morphology was obtained.

(3) When the high permeability coat A was used, the effect of the casting thickness in the stairway type pattern on the microstructure was not significant. The average grain size of the magnesium alloy was slightly decreased by the application of the reduced pressure. The microstructures were the same as those of magnesium alloy castings made by a general sand mold.

(4) To apply the excessive high reduced pressure caused "forward flow of molten metal" and changed the melt surface from convex to concave. Further, it caused the occurrence of internal defects such as cold shut laps or folds in the castings.

\section{REFERENCES}

1) M. Marlatt, D. Weiss and J. N. Hryn: Magnesium Technology 2003, (TMS, 2003) pp. 141.

2) Z. Liu, J. Hu, Q. Wang, W. Ding, Y. Zhu, Y. Lu and W. Chen: J. Mater. Proc. Tech. 120 (2002) pp. 94.

3) for example, I. Ohnaka: Computer Den-netsu Gyoukokaiseki Nyumon (Maruzen, Japan) (1990) pp. 326.

4) S. Koroyasu and M. Matsuda: J. JFS 76 (2004) 679-686.

5) S. Koroyasu and M. Matsuda: J. JFS 76 (2004) 687-694.

6) S. Koroyasu and M. Matsuda: J. JFS 68 (1996) 949-955.

7) C. Goria, G. Del Gaudio, G. Caironi, G. Silva and M. Selli: Trans. AFS 94 (1986) 589-594.

8) R. P. Walling and J. A. Dantzig: Proceedings of EPC: Managing the Technology Sponsored by AFS, Alabama (1993) 10-1.

9) H. Takeuchi, M. Shimizu, Y. Matsuda and Y. Aida: IMONO 59 (1987) $748-753$.

10) T. Kobayashi and T. Maruyama: Mater. Trans. 44 (2003) 2404-2409.

11) G. S. Cho, K. W. Lee, S. K. Kim, H. H. Jo, S. C. Lim and W. Y. Kim: THERMEC 2003, Material Science Forum (2003) pp. 623.

12) T. V. Molibog and H. Littleton: Lost Foam Casting (AFS 105th Casting Congress) (2001) pp. 73.

13) Y. Sakaguchi: IMONO 63 (1991) 488-493. 